fees from Union Chimique Belge Pharma, personal fees from Pfizer, outside the submitted work.

DOI: 10.1136/annrheumdis-2020-eular.1080

\section{THU0420 ULTRASOUND SHOWS GREAT ACCURACY FOR THE DIAGNOSIS OF CRYSTAL ARTHRITIS IN PATIENTS WITH RECENT-ONSET SYNOVITIS}

E. Cipolletta ${ }^{1}$, A. DI Matteo ${ }^{1,2}$, E. Filippucci ${ }^{1}$, W. Grassi ${ }^{1} .{ }^{1}$ Polytechnic University of Marche, Rheumatology Unit - Department of Clinical and Molecular Sciences, Jesi, Italy; ${ }^{2}$ University of Leeds, Leeds Institute of Rheumatic and Musculoskeletal Medicine, Leeds, United Kingdom

Background: The value of ultrasound (US) in the diagnosis of crystal arthropathy, such as gout or calcium pyrophosphate deposition disease (CPPD), in patients with recent onset synovitis has been evaluated only by a few studies. Objectives: To investigate, in patients with acute arthritis, the accuracy of US for the diagnosis of crystal arthropathy.

Methods: Consecutive patients with recent onset ( $<6$ weeks) acute arthritis were enrolled. The US examinations were performed a rheumatologist blinded to clinical data. Calcium pyrophosphate and monosodium urate crystal deposits were identified in the joint affected by synovitis (target joint), as well as in the classic sites for gout and CPPD (set of joint) (Table 1), according to the OMERACT definitions.

Table 1. Anatomical targets of ultrasound examination

\begin{tabular}{|c|c|c|c|}
\hline & Gout & CPPD & Both \\
\hline Wrist & $\begin{array}{l}\text { Radiocarpal j } \\
\text { Intercarpal j }\end{array}$ & $\begin{array}{l}\text { Triangular FC complex } \\
\text { Scapho-lunate ligament }\end{array}$ & / \\
\hline $\begin{array}{l}\text { Hand } \\
\text { Knee }\end{array}$ & $\begin{array}{l}\text { DC in the II MCPj HC } \\
\text { Popliteal groove }\end{array}$ & $\begin{array}{l}\text { Deposits within the II MCPj HC } \\
\text { Meniscal FC }\end{array}$ & $\begin{array}{l}\text { II MCPj } \\
\text { Supra-patellar }\end{array}$ \\
\hline & $\mathrm{DC}$ in the femoral condyle's $\mathrm{HC}$ & $\begin{array}{l}\text { Deposits within the femoral } \\
\text { condyles' } \mathrm{HC}\end{array}$ & recesses \\
\hline Hip & $\mathrm{DC}$ in the femoral head's $\mathrm{HC}$ & $\begin{array}{l}\text { Deposits within the femoral } \\
\text { head's HC } \\
\text { Acetabular FC }\end{array}$ & Hip j \\
\hline Foot & $\mathrm{DC}$ in the I MTPj HC & Deposits within I MTPj HC & I MTPj \\
\hline
\end{tabular}

Legend. DC: double contour, FC: fibrocartilage, HC: hyaline cartilage, MCPj: metacarpophalangeal joint, MTPj: metatarsophalangeal joint, j: joint.

The diagnostic accuracy of US and synovial fluid analysis (SFA) was evaluated taking the classification criteria for gout and CPPD as gold standard $(1,2)$. Moreover, the US and SFA results were compared in the joints in which the SFA was performed.

Results: One-hundred and four patients were enrolled: 22 CPPD patients, 23 with gout and 59 disease controls. Table 2 reports the diagnostic accuracy of US and SFA, using the classification criteria as gold standard.

Table 2. Diagnostic accuracy of US and SFA

\begin{tabular}{lcccc}
\hline & Sensitivity & Specificity & Positive LHR & Negative LHR \\
\hline US (target joint) & & & & \\
Crystal arthritis & 0.84 & 0.91 & 9.5 & 0.2 \\
& $(0.7-0.93)$ & $(0.8-0.97)$ & $(4.1-22)$ & $(0.1-0.3)$ \\
CPPD & 0.91 & 0.91 & 10.2 & 0.1 \\
& $(0.71-0.99)$ & $(0.80-0.97)$ & $(4.4-23.8)$ & $(0-0.4)$ \\
Gout & 0.83 & 0.91 & 9.1 & 0.2 \\
& $(0.61-0.97)$ & $(0.80-0.97)$ & $(3.9-21.4)$ & $(0.1-0.5)$ \\
US (set of joints) & & & & \\
Crystal arthritis & 0.96 & 0.87 & 7.6 & 0.1 \\
& $(0.85-0.99)$ & $(0.76-0.95)$ & $(3.8-15.3)$ & $(0-0.2)$ \\
CPPD & 1 & 0.88 & 8 & 0 \\
& $(0.85-1)$ & $(0.76-0.95)$ & $(4-16)$ & $(0-0.2)$ \\
Gout & 0.91 & 0.88 & 7.3 & 0.1 \\
& $(0.72-0.99)$ & $(0.76-0.95)$ & $(3.6-14.8)$ & $(0-0.4)$ \\
SFA & 0.9 & 1 & & 0.1 \\
Crystal arthritis & $(0.77-0.97)$ & $(0.94-1)$ & & $(0-0.2)$ \\
CPPD & 0.90 & 1.0 & $/$ & 0.1 \\
& $(0.7-0.99)$ & $(0.94-1)$ & & $(0-0.3)$ \\
Gout & 0.91 & 1 & $/$ & 0.1 \\
& $(0.71-0.99)$ & $(0.94-1)$ & & $(0-0.3)$ \\
\hline
\end{tabular}

Legend. LHR: likelihood ratio

SFA was performed in 67 knees $(64.4 \%), 10$ wrists $(9.6 \%), 10$ ankles $(9.6 \%), 5$ I MTP joints (4.8\%), 5 hips $(4.8 \%), 4$ elbows $(3.8 \%), 4$ shoulders $(3.8 \%)$.

The total agreement between US and SFA was excellent ( $93.8 \%$ in CPPD and $90.2 \%$ in gout) SFA positive/US negative results occurred in 1 patient with CPPD $(1.2 \%)$ and in 4 patients with gout $(4.9 \%)$. On the contrary, US positive/SFA negative results occurred in 4 patients with CPPD $(4.9 \%)$ and in 4 patients with gout $(4.9 \%)$

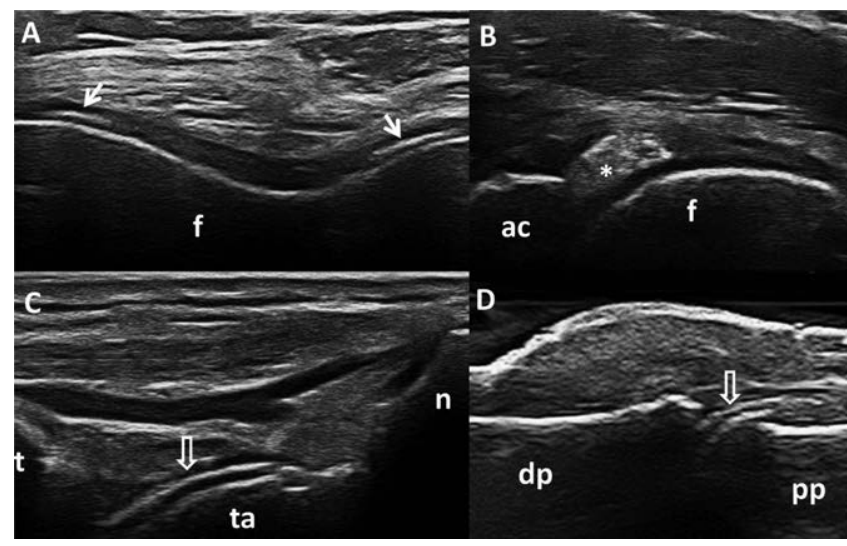

Figure 1 provides a pictorial evidence of the US appearance of crystal deposits. A: anterio suprapatellar transverse scan of the femoral condylar HC. HC calcifications (arrows) B: anterior longitudinal scan of the hip. FC calcification (asterisk) C: anterior longitudinal scan of the ankle. DC sign (void arrow) .D: dorsal longitudinal scan of distal interphalangeal joint. DC sign (void arrow).

Conclusion: US is useful for the diagnosis of gout and CPPD in patients with acute synovitis. Extending the US evaluation to the joints which are most commonly involved in gout and in CPPD, other than those affected by synovitis, increases the sensitivity of US.

References:

[1] Neogi T, et al. 2015 Gout classification criteria: an ACR/EULAR collaborative initiative. Ann Rheum Dis 2015

[2] McCarty D. CPPD Disease: Nomenclature and Diagnostic Criteria. Ann Intern Med 1977

Disclosure of Interests: : Edoardo Cipolletta: None declared, Andrea Di Matteo Grant/research support from: the publication was conducted while Dr. Di Matteo was an ARTICULUM fellow, Emilio Filippucci Speakers bureau: Dr. Filippucci reports personal fees from AbbVie, personal fees from Bristol-Myers Squibb, personal fees from Celgene, personal fees from Roche, personal fees from Union Chimique Belge Pharma, personal fees from Pfizer, outside the submitted work. Walter Grassi Speakers bureau: Prof. Grassi reports personal fees from AbbVie, personal fees from Celgene, personal fees from Grünenthal, personal fees from Pfizer, personal fees from Union Chimique Belge Pharma, outside the submitted work.

DOI: 10.1136/annrheumdis-2020-eular.1100

\section{THU0421 TUMOR-INDUCED OSTEOMALACIA: DATA FROM A MONOCENTRIC EXPERIENCE ON 16 PATIENTS}

C. Crotti ${ }^{1}$, F. Bartoli ${ }^{1}$, M. Manara ${ }^{1}$, P. A. Daolio ${ }^{2}$, F. Zucchi $^{1}$, R. Caporali ${ }^{1,3}$, L. Sinigaglia', M. Varenna'. ' Gaetano Pini Institute, Dept of Rheumatology, Milan, Italy; ${ }^{2}$ Gaetano Pini Institute, Dept of Orthopedics, Milan, Italy; ${ }^{3}$ University of Milan, Dept of Clinical Sciences \& Community Health, Milan, Italy

Background: Tumor-induced osteomalacia (TIO) is a rare paraneoplastic syndrome due to a phosphaturic tumor, which overproduces fibroblast growth factor-23 (FGF-23), causing hyperphosphaturia, hypophosphoremia, low 1,25(OH) $\mathrm{VitD}_{3}$ and osteomalacia. Locating the tumor is critical, because lesions are typically small, benign mesenchymal tumors, anywhere in the body; the delay between onset of symptoms and diagnosis ranges from 2.5-28 years. Surgical removal is the only effective therapeutic approach.

Objectives: To retrospectively evaluate patients affected by $\mathrm{TIO}$, investigating clinical management and disease outcome.

Methods: We retrospectively collected data of patients affected by TIO referred to a tertiary Rheumatology Center between Sep 2000 and Jan 2020.

Results: We included 16 patients with a definite diagnosis of TIO, mean age \pm standard deviation $62.4 \pm 14.6 \mathrm{yrs}, 56.2 \%$ females, mean age at symptoms onset $48.0 \pm 14.3$ yrs $(53.8 \pm 13.1$ at diagnosis). Mean diagnostic delay between symptoms onset and tumor detection was $6.8 \pm 6.4 \mathrm{yrs}$. All patients complained bone pain, muscle weakness, and fractures before diagnosis of TIO. Biochemical findings were: mean serum Phosphorus (PS) $1.4 \pm 0.4 \mathrm{mg} /$ $\mathrm{dL}$ (reference range (RR) 2.5-4.6), mean serum Calcium $9.4 \pm 0.7 \mathrm{mg} / \mathrm{dL}$ (RR 8.4-10.2), mean serum 1,25(OH) $\mathrm{V}^{\mathrm{VitD}} 330.5 \pm 23.4 \mathrm{ng} / \mathrm{L}$ (RR 25-86). Intact-FGF-23 was dosed in 9 patients, always resulting elevated: mean $396.6 \pm 707.3 \mathrm{pg} / \mathrm{mL}$ (RR 25-45). PTH was increased in $30 \%$ of cases, while serum alkaline phosphatase was increased in $87.5 \%$. 24h-Urine Phosphorus (PU) was increased in only $13 \%$ of patients, but, when renal phosphate 
wasting by tubular reabsorption of phosphate (TRP) was calculated, PU resulted increased in all.

Tumor was localized in all cases (Fig.1) and were localized in bone and soft tissue, by using functional imaging, followed by anatomical techniques. Before the introduction in routinely practice of ${ }^{68} \mathrm{Ga}$-DOTATATE-PET-CT in 2013, Octreoscan-SPECT/CT and ${ }^{18} \mathrm{~F}$ FDG-PET were used as imaging modalities. Since 2013, diagnostic delay consistently reduced, from $8.6 \pm 8.3 \mathrm{yrs}$ (7 patients) to $4.5 \pm 2.6$ yrs (9 patients), confirming higher diagnostic accuracy of ${ }^{68} \mathrm{Ga}$-DOTATATE-PET-CT.

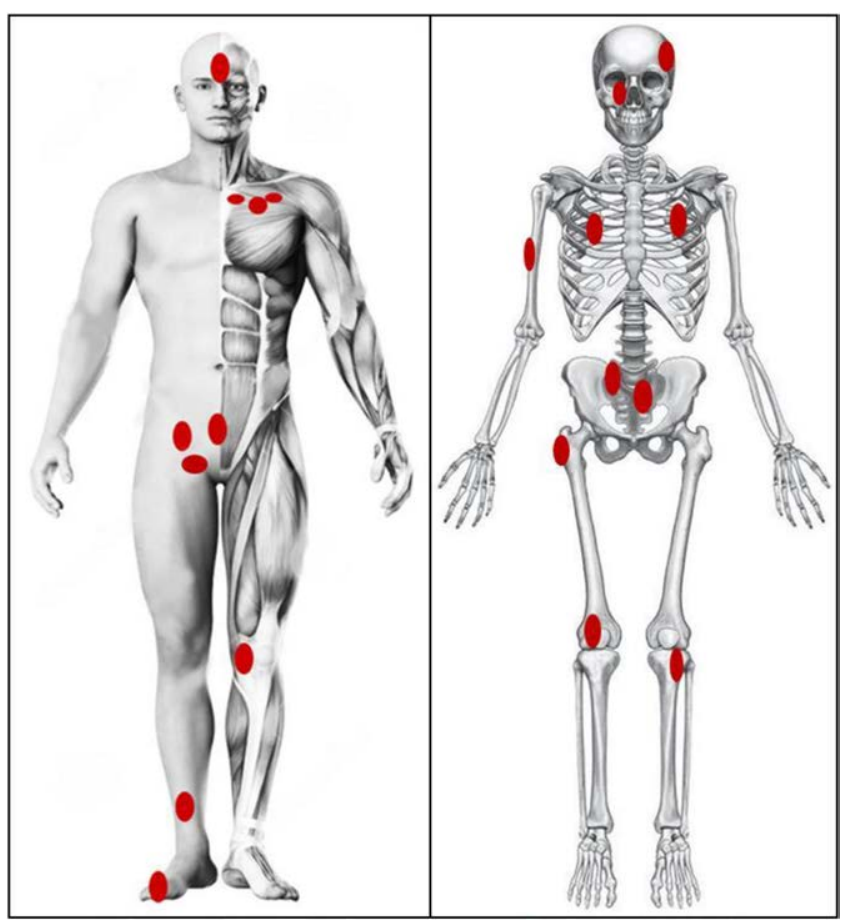

Figure 1.

13 patients underwent surgery; in two cases surgery was not possible due to tumor location, so pharmacological support with phosphate supplements and calcitriol was started; a patient underwent to TC-guided radiofrequency ablation. After surgery, 7 patients experienced a complete remission, 3 had a persistence of the disease, and 3 an overtime relapse, even after a longstanding normalization of PS (6 years). After surgical tumor removal, PS significantly increased in few days (from $1.36 \pm 0.39$ to $2.9 \pm 1.1, p=0.0001$ ), while iFGF-23 levels tended to rapidly decreased (from $396.6 \pm 707.3$ to $62.8 \pm 78.4$ ). Before the introduction of ${ }^{68} \mathrm{Ga}$-DOTATATE-PET-CT, 6 patients underwent to imaging-guided closed biopsy to confirm tumor localization; by using ${ }^{68} \mathrm{Ga}$-DOTATATE-PET-CT only 2 subjects had closed biopsy. Furthermore, in our population only patients who had biopsy to detect the lesion (7 patients) had relapses compared to patients who did not

Conclusion: To our knowledge, this is the widest European cohort of patients affected by TIO reported in the last two decades. We confirm an important delay between symptoms onset and diagnosis. To locate tumor, a stepwise approach is recommended, starting with a thorough medical history and physical examination, followed by functional imaging, preferring ${ }^{68} \mathrm{Ga}$-DOTATATE-PET-CT. Tumor biopsy is not recommended due to the potential cell spilling. Surgery is considered the only definitive treatment, aiming to a wider excision. Active surveillance is always needed, due to the possible relapses, even after a long period of complete clinical and biochemical remission.

Disclosure of Interests: : Chiara Crotti: None declared, Francesca Bartoli: None declared, Maria Manara Consultant of: Consultant and/or speaker for Eli-Lilly, MSD, Sanofi-Genzyme, Novartis, Alfa Wasserman and Cellgene, Speakers bureau: Consultant and/or speaker for Eli-Lilly, MSD, Sanofi-Genzyme, Novartis, Alfa Wasserman and Cellgene, Primo Andrea Daolio: None declared, Francesca Zucchi: None declared, Roberto Caporali Consultant of: AbbVie; Gilead Sciences, Inc.; Lilly; Merck Sharp \& Dohme; Celgene; Bristol-Myers Squibb; Pfizer; UCB, Speakers bureau: Abbvie; Bristol-Myers Squibb; Celgene; Lilly; Gilead Sciences, Inc; MSD; Pfizer; Roche; UCB, Luigi Sinigaglia: None declared, Massimo Varenna: None declared

DOI: 10.1136/annrheumdis-2020-eular.4486

\section{THU0422 \\ CALCIUM PYROPHOSPHATE CRYSTAL DEPOSITION WITHIN TOPHUS LOBULE: A FREQUENT ASSOCIATION OBSERVED IN LONG-TIME COURSE TOPHI}

H. K. Ea ${ }^{1}$, O. Olivier ${ }^{1}$, N. N. Pham ${ }^{2}$, V. Frochot ${ }^{3}$, D. Bazin ${ }^{4}$, C. Marty ${ }^{1}$, A. Ostertag ${ }^{1}$, J. D. Laredo ${ }^{5}$, P. Richette ${ }^{1}$, Q. D. Nguyen ${ }^{6}$, T. Bardin ${ }^{1} .{ }^{1}$ Universite de Paris, UMR 1132, BIOSCAR, Paris, France; ${ }^{22}$ French-Vietnamese Research Center on Gout and Chronic Diseases, Vien Gut Medical Clinic., Ho Chi Minh City, Vietnam: ${ }^{3}$ HUEP - Hôpital Tenon, Sorbonne Universite - UMR S1155, Explorations Fonctionnelles Multidisciplinaires, Paris, France; ${ }^{4}$ Institut de Chimie Physique, Université Paris-Saclay et CNRS - UMR8000, Orsay, France; ${ }^{5}$ Hôpital Lariboisière, Service de Radiologie, Paris, France; ${ }^{6}$ French-Vietnamese Research Center on Gout and Chronic diseases, Vien Gut Medical Clinic., Ho Chi Minh City, Vietnam

Background: Calcium pyrophosphate (CPP) crystals and monosodium urate (MSU) crystals are frequently found in the same synovial fluids of gouty patients suggesting an interaction in crystal formation and deposition. This association has never been reported in tophus.

Objectives: we aimed to describe the prevalence of CPP crystal deposition in tophus and to determine the associated risk factors.

Methods: 22 tophi consecutively harvested were fixed in $4 \%$ paraformaldehyde and embedded in paraffin. $5-\mu \mathrm{m}$ thick sections were analyzed by compensated polarized microscopy (CPM) after hematoxylin and eosin staining. Characterization of CPP crystals were performed by scan electronic microscopy (SEM) and Fourier transform infrared (FTIR) spectroscopy. Clinical characteristics were compared between patients having tophus with CPP deposition and patients having tophus without CPP crystals.

Results: All tophi appeared multi-lobulated depositions of MSU crystals separated by fibrous tissue and surrounded by a foreign giant cell reaction. CPP crystals were identified in few lobules of 5 tophi (22.7\%) harvested from 3 great toes, 1 elbow bursa and 1 finger of 5 patients. CPP crystals formed aggregate deposition within the lobule of MSU crystals. Both monoclinic and triclinic CPP crystal phases were identified by CPM, SEM and FTIR. Tophi were harvested from 22 male gouty patients with a mean age of $50.8(28-66)$ years and a mean BMl of $24.2 \mathrm{~kg} / \mathrm{m} 2$ (18.9-29.4). Mean serum urate level (SUL) was $499 \pm 107 \mu \mathrm{mol} / \mathrm{L}$. 59\% of patients had chronic renal disease stage 2 or $3,40.9 \%$ dyslipidemia, $22.7 \%$ type 2 diabetes mellitus, $13.6 \%$ hypertension and $50 \%$ obesity. Patients with tophi containing CPP deposition were older (61.2 [56-66] vs 47.8 [28-64] years, $\mathrm{p}=0.009$ ) and had a longer gout duration (19 [10-31] vs 9 [3-20] years, $p=0.007$ ) and tophus duration (11.4 [8-16] vs 4.5 [1-9] years, $p<0.0001$ ) than patients with tophi alone. Tophi did not display calcification on radiographies performed before surgery. However, the density of tophi containing CPP crystal deposition was higher than the density of tophi without CPP crystals (51 [25-100] vs $21.5 \%$ [0-40], $p=0.009$ ). The proportion of bone erosion and gout arthropathy was similar between the two groups. Similarly, no difference was observed for SUL $(467 \pm 43$ vs $509 \pm 109 \mu \mathrm{mol} / \mathrm{L})$, estimated glomerular filtration rate $(76.6 \pm 11.9$ vs $74.9 \pm 15.7 \mathrm{ml} / \mathrm{min} / 1.73 \mathrm{~m} 2)$ and prevalence of comorbidities. Interestingly, no calcification was detected on knee and wrist radiographies of patients with tophi containing CPP deposition.

Conclusion: These results reported for the first time, in a small sample size, that CPP crystal deposition occurred within tophus lobules. They suggested that long-time course tophi might act as a facilitating agent of CPP nucleation. This hypothesis needs specific confirmation studies

Disclosure of Interests: : None declared

DOI: 10.1136/annrheumdis-2020-eular.6057

\begin{tabular}{l|l}
\hline THU0423 & ADHERENCE TO URATE-LOWERING THERAPY IN \\
PATIENTS WITH SEVERE GOUT WHO RECEIVED \\
CANAKINUMAB FOLLOWING A 5-YEAR \\
RETROSPECTIVE ANALYSIS
\end{tabular}

M. Eliseev ${ }^{1}$, O. Sheliabina ${ }^{1} .{ }^{1}$ V.A. Nasonova Research Institute of Rheumatology, Moscow, Russian Federation

Background: The adherence to lowering therapy for gout is low, including in chronic severe gout. Whether interleukin 1 inhibitors may contribute to better adherence is unknown.

Objectives: To compare adherence to urate-lowering therapy in patients with severe gout who received canakinumab versus patients who received standard anti-inflammatory therapy (NSAIDs, glucorticoids, colchicine).

Methods: Of the 513 patients with gout observed at the V.A. Nasonova Research Institute of Rheumatology, Moscow from 2013 to 2014 y 247 patients with the most severe gout, requiring regular symptomatic treatment, were selected. Of these, 25 patients $(3(12 \%)$ women and $22(88 \%)$ men), the average age of $54.5 \pm 12.7 \mathrm{~g}$, received (at least 1) canakinumab injection of $150 \mathrm{mg}$ subcutaneously as a symptomatic therapy, the remaining 222 patients (men) mean age 